\title{
PEMANFAATAN CENDAWAN MIKORIZA ARBUSKULAR UNTUK MEREDUKSI KADAR Pb DAN Cd PADA LAHAN SAWAH SERTA PENGARUHNYA TERHADAP PERTUMBUHAN TANAMAN SELADA
}

\author{
Arbuscular Mycorrhizal Fungi Utilization for Reduction Pb and Cd Content in Rice Field, \\ and Its Effect on Lettuce Growth \\ ${ }^{1 *}$ Marhamah Nadir, ${ }^{2}$ Syamsia, ${ }^{3}$ Sartika Laban \\ ${ }^{1}$ Jurusan Nutrisi dan Makanan Ternak, Fakultas Peternakan, Universitas Hasanuddin; ${ }^{2}$ Fakultas Pertanian, \\ Universitas Muhammadiyah, ${ }^{3}$ Departemen Ilmu Tanah, Fakultas Pertanian, Universitas Hasanuddin \\ Corresponding email: marhamahnadir@unhas.ac.id
}

\begin{abstract}
$\mathrm{Pb}$ and $\mathrm{Cd}$ are two types of heavy metal that has been widely contaminates agricultural land. Pollution on agricultural land led to a decrease in productivity, disruption of the ecological balance and impaired human health. The research aims to identify and detect the content of heavy metals $\mathrm{Cd}$ and $\mathrm{Pb}$ in the soil and measure the effectiveness of the arbuscular mycorrhizal veskular withstand heavy metals in lettuce plants. Soil samples were collected in the Village Sudiang Makassar City using stratified sampling and purposive sampling methods. Sampling points are distinguished based on the distance from the highway, which is 15 meters and 30 meters. Analysis of heavy metal content in soil carried Soil Laboratory BPTP Maros. The study based on a randomized block design in a factorial 2 factors. The first factor was soil sampling and the second factor was the provision of mycorrhizae. Based on the survey results revealed that the content of $\mathrm{Pb}$ and $\mathrm{Cd}$ in soil belt of northern South Sulawesi has passed the threshold. Due to the reduced content of $\mathrm{Pb}$ and $\mathrm{Cd}$ after treatment arbuscular mycorrhizal fungi but the decline is not significant compared with no treatment mycorrhizae. The content of $\mathrm{Cd}$ and $\mathrm{Pb}$ in plants of lettuce grown in the various media and the addition of CAM treatments above the threshold concentration safe for consumption.
\end{abstract}

Keywords: heavy metal, mycorrhizae, lettuce.

\section{PENDAHULUAN}

$\mathrm{Pb}$ dan $\mathrm{Cd}$ adalah dua jenis logam berat yang sudah banyak mencemari tanah pertanian dan bahan pangan yang dihasilkan. Kedua jenis logam berat tersebut bisa berasal dari batuan induk tanah itu sendiri, pupuk fosfat alam serta bahan bakar kendaraan bermotor, namun bahan bakar fosil menjadi penyebab terbesarnya.

Pencemaran pada lahan pertanian bukan hanya sebatas pada penurunan produktifitas, gangguan pada keseimbangan ekologis tetapi akibat lebih jauh adalah gangguan pada kesehatan manusia. Menurut Abbdurrahman Ali (2003), dari sawah seluas 106 ribu ha di Karawang dan Bekasi, para peneliti Puslitbang tanah menemukan adanya pencemaran $\mathrm{Cd}$ pada areal sekitar 4\% agak tercemar, 3,3\% sisanya tidak tercemar. Kadar $\mathrm{Pb}$ dalam tanah berkisar antara 7,83 - 91,47 ppm, sedangkan kadar $\mathrm{Cd}$ antara 0,875 ppm. Batas ambang $\mathrm{Pb}$ dalam tanah adalah 1,0 ppm, sedangkan $\mathrm{Cd}$ ditetapkan sebesar 0,24 ppm. Kadar Pb pada bawang merah di sentra produksi bawang di Tegal dan Bekasi berkisar antara 2,46 - 3,67 ppm, padahal batas ambang $\mathrm{Pb}$ dalam sayuran adalah 2,0 ppm. Kadar $\mathrm{Cd}$ pada bawang tersebut $0,135-0,285 \mathrm{ppm}$, sedangkan batas ambangnya adalah $0,1 \mathrm{ppm}$

Kondisi lahan pertanian yang semakin bergeser karena perluasan sarana transportasi dan sangat dekat dengan pusat lalu lintas darat menjadi kajian yang menarik untuk melakukan penelitian terhadap kandungan logam berat lahan persawahan. 
Khususnya yang berada di pinggir jalan raya jalur utara Sulawesi Selatan (Kementrian Negara dan Lingkungan Hidup RI, 2007).

Salah satu upaya untuk mengurangi dampak pencemaran tersebut dilakukan upaya pencegahan dengan sistem budidaya ramah lingkungan dengan mengaplikasikan cendawan mikoriza arbuskular (CMA) dan pupuk organik. CAM dan pupuk organik berfungsi untuk menahan logam berat tersebut agar tidak terserap sampai ke jaringan tanaman, atau mengurangi kadar logam berat sehingga tanaman aman dikonsumsi.

Lahan persawahan di pinggir jalan jalur utara Sulawesi Selatan, yakni Makassar Utara dipilih sebagai lokasi pengambilan sampel, dengan pertimbangan jalur tersebut sangat padat oleh kendaraan bermotor. Jalur utara tidak hanya menghubungkan daerah-daerah di Sulawesi Selatan namun juga menjadi jalur penghubung antar propinsi di Sulawesi Selatan.

Selada dipilih sebagai tanaman contoh, dengan asumsi, selada adalah tanaman yang dijadikan lalapan, dikonsumsi tanpa melalui proses pemasakan. Perubahan perilaku konsumsi masyarakat yang semakin sering mengkonsumsi makanan barat yang banyak menyajikan selada sebagai lalapan ataupun sebagai advertise.

Penelitian bertujuan untuk mengetahui dan mendeteksi kandungan logam berat $\mathrm{Cd}$ dan $\mathrm{Pb}$ pada tanah persawahan di sepanjang jalur utara Sulawesi Selatan yang terabsorbsi pada selada dan mengukur efektifitas mikoriza veskular arbuskular (CAM) dalam menahan logam berat pada tanaman selada. Penelitian ini dapat menjadi informasi keamanan dan kelayakan konsumsi pangan, khususnya tanaman pangan dan hortikultura yang ditanam di lahan persawahan disepanjang jalur utara Sulawesi Selatan sehingga menjadi bahan pertimbangan masyarakat dalam mengkomsumsi sayuran mentah.

\section{METODE PENELITIAN}

Sampel tanah diambil dari lahan persawahan jalan poros Makassar- Maros, kelurahan Sudiang Kotamadya Makassar. Analisis kandungan logam berat tanah dilakukan di Laboratorium Tanah BPTP Kabupaten Maros. Penanaman dilaksanakan di Kelurahan Tamalanrea Makassar.

Sampel tanah diambil di Kelurahan Sudiang Kota Makassar dengan menggunakan metode stratified sampling dan purposive sampling. Titik pengambilan sampel dibedakan berdasarkan jarak dari jalan raya, yaitu 15 meter dan 30 meter. Kedalaman tanah adalah $4 \mathrm{~cm}$ dan $8 \mathrm{~cm}$. Kontrol diambil dari tanah di halaman rumah di kebun yang jauh dari polusi kendaraan bermotor.

\section{Metodologi}

Penelitian disusun berdasarkan Rancangan Acak Kelompok (RAK) dalam faktorial yang terdiri dari 2 faktor. Faktor pertama pengambilan sampel tanah yang terdiri dari Kontrol (J0), jarak 15 meter (J1) dan jarak 30 meter (J2), sedangkan faktor kedua adalah pemberian mikoriza $(\mathrm{M})$ yang terdiri dari kontrol/tanpa CAM (M0) dan 10 gram/ polybag (M1), sehingga terdapat 6 kombinasi perlakuan yang terdiri atas 3 kelompok yang masing-masing kelompok perlakuan terdiri dari 2 polybag, sehingga terdapat 36 unit pengamatan. Kombinasi perlakuan J0M0: Kontrol tanpa mikoriza, J0M1 : Kontrol + mikoriza, J1M0 : Jarak 15 $\mathrm{m}$ tanpa mikoriza, J1M1 : Jarak $15 \mathrm{~m}+10$ gr mikoriza, J2M0 : Jarak $30 \mathrm{~m}$ tanpa mikoriza, J2M1 : Jarak $30 \mathrm{~m}+$ mikoriza.

\section{Pelaksanaan}

Tanah diukur kadar Cd dan Pbnya, selanjutnya dilakukan pencampuran pupuk organik dan tanah $(1: 1)$ secara merata ke dalam media tanam kemudian dimasukkan ke dalam pot berukuran $2 \mathrm{~kg}$. Media tanam disiram sehingga tercapai kondisi yang 
lembab. Benih selada direndam di dalam air dingin atau air hangat-hangat kuku selama \pm 15 menit, lalu ditiriskan (dikeringkan) kembali. Benih kemudian disemai pada media yang telah lembab selama 12 hari, dengan membenamkannya pada lubang yang telah ditekan sedalam $1 / 2 \quad-1 \mathrm{~cm}$, selanjutnya ditutup dengan tanah tipis dan halus. Inokulum CAM sesuai perlakuan pada setiap polybag. Tanaman dipelihara selama 6 minggu sesuai teknik budaya selada dengan melakukan pemberian pupuk organik cair "BIO-CARE PLUS" setiap minggu. Selada di panen pada umur 6 minggu.

\section{HASIL DAN PEMBAHASAN}

\section{Pertumbuhan Tanaman}

Hasil uji lanjutan BNJ Jumlah daun dan berat basah pada umur 6 MST disajikan pada Tabel 1.

Tabel 1. Hasil Uji lanjutan BNJ jumlah daun pada 6 MSPT.

\begin{tabular}{ccc}
\hline $\begin{array}{c}\text { KOMBINASI } \\
\text { PERLAKUAN }\end{array}$ & $\begin{array}{c}\text { RATA-RATA } \\
\text { JUMLAH } \\
\text { DAUN }\end{array}$ & $\begin{array}{c}\text { BERAT } \\
\text { (gr) }\end{array}$ \\
\hline J0M0 & $4,67^{\mathrm{a}}$ & 2,16 \\
J0M1 & $5,00^{\mathrm{a}}$ & 3,46 \\
J1M0 & $5,00^{\mathrm{a}}$ & 4,23 \\
J1M1 & $5,60^{\mathrm{a}}$ & 5,33 \\
J2M0 & $6,60^{\mathrm{b}}$ & 6,40 \\
J2M1 & $7,60^{\mathrm{c}}$ & 8,23 \\
\hline
\end{tabular}

Ket. Angka yang diikuti oleh huruf yang berbeda menunjukkan perbedaan antara perlakuan pada taraf 0,05 .

Berdasarkan hasil pada Tabel 1 . Jumlah daun yang tertinggi adalah perlakuan J2M1 yaitu, sampel tanah yang berasal dari jarak 30 meter dan diberikan perlakuan mikoriza, hasil tersebut berbeda nyata dengan perlakuan JIMO dan JOM1. Pada Tabel 1 secara umum dapat dilihat bahwa rata-rata jumlah daun pada perlakuan M1 (inokulasi CMA) cenderung lebih tinggi dibandingkan dengan perlakuan lainnya . Hal ini diduga karena pada umur 2 MST tanaman mulai merespon perlakuan.

Hasil tersebut menunjukkan bahwa perlakuan mikoriza memberikan pengaruh yang nyata terhadap pertumbuhan tanaman. Hal ini sesuai penelitian Iriani (2003) Kondisi ini dapat menggambarkan bahwa CMA secara umum mampu berperan dalam menyediakan nutrisi bagi pertumbuhan tanaman muda. Parameter jumlah daun tanaman lebih baik pada media yang mengandung spesies CMA, hal ini diduga karena serapan nutrisi lebih terstimulasi oleh CMA sehingga dapat dimanfaatkan lebih efisien oleh tanaman untuk proses awal pertumbuhannya.

Peran mikoriza sebagai sumber pupuk hayati terutama sebagai penyumbang nutrisi bagi tanaman pada lahan-lahan kahat $\mathrm{P}$ dengan kelarutan Al tinggi, sudah tidak perlu diragukan lagi. Umumnya peran mikoriza menjadi efektif dan efisien pada lahan-lahan yang tergolong relatif miskin hara. Pada tanah dengan kandungan unsur $\mathrm{P}$ alam rendah, secara teoritis mempunyai kandungan cendawan mikoriza indigen yang mampu berasosiasi dengan akar tanaman yang tumbuh di sekelilingnya, karena tingkat kolonisasi mikoriza adalah berbanding terbalik dengan tingkat ketersediaan $\mathrm{P}$ dalam tanah.

Hasil penelitian menunjukkan bahwa rata-rata bobot basah tanaman selada tertinggi pada perlakuan J2M1 yaitu, sampel tanah yang berasal dari jarak 30 meter dan diberikan perlakuan mikoriza, hasil tersebut berbeda nyata dengan perlakuan J0M1 dan J1M1. Hal ini berkaitan dengan jumlah daun tanaman selada pada perlakuan J2M1 yang cenderung lebih tinggi dibandingkan dengan perlakuan lainnya. Semakin banyak jumlah daun maka semakin meningkat total luas daun tanaman. Dengan semakin meningkatnya total luas daun kemampuan tanaman untuk melakukan fotosintesis semakin tinggi dan berpengaruh pada bobot basah tanaman. Meningkatnya bobot basah 
tanaman selada pada perlakuan J2M1 diduga dipacu oleh pemberian CAM pada media tanam memperbaiki kondisi perakaran tanaman. Perkembangan dan kepadatan spora secara positif berkorelasi dengan peningkatan kolonisasi akar sehingga penyerapan unsur hara akan lebih baik dan akan mendukung pertumbuhan tanaman yang lebih baik seperti pada jumlah daun.

\section{Kandungan $\mathrm{Pb}$ dan $\mathrm{Cd}$}

Hasil Analisis kandungan $\mathrm{Cd}$ dan $\mathrm{Pb}$ tanah sebelum penanaman dan pemberian CAM disajikan pada Tabel 2.

Tabel 2. Hasil Analisis kandungan $\mathrm{Pb}$ dan $\mathrm{Cd}$ pada tanah sebelum perlakuan pemberian CAM

\begin{tabular}{ccc}
\hline Perlakuan & \multicolumn{2}{c}{$\begin{array}{c}\text { Kandungan Logam } \\
\text { Berat }(\mathbf{m g} / \mathbf{k g})\end{array}$} \\
\cline { 2 - 3 } & $\mathrm{Pb}$ & $\mathrm{Cd}$ \\
\hline $\mathrm{J} 0$ & 133,456 & 0,682 \\
$\mathrm{JI}$ & 158,621 & 1,434 \\
$\mathrm{~J} 2$ & 143,842 & 1,439 \\
\hline
\end{tabular}

Konsentrasi $\mathrm{Pb}$ pada tanah yang diambil dari lokasi tepi jalan (jarak $15 \mathrm{~m}$ ) lebih tinggi dari jarak $30 \mathrm{~m}$ dan tanah yang diambil dari pekarangan. Namun demikian secara keseluruhan tanah yang dianalisis menunjukkan tingginya konsentrasi logam berat $\mathrm{Pb}$ dan $\mathrm{Cd}$ dan telah berada diatas ambang normal. Menurut Peterson dan Alloway (1979) dalam Darmono (1995) kandungan rata-rata $\mathrm{Pb}$ dalam tanah secara alamiah adalah $10 \mu \mathrm{g} / \mathrm{g}$ dan $\mathrm{Cd} 0,06 \mu \mathrm{g} / \mathrm{g}$ tanah. Dari hasi diatas diduga kandungan $\mathrm{Pb}$ dan $\mathrm{Cd}$ mencemari tanah pertanian melalui penggunaan bahan kimia/pupuk kimia pada lahan persawahan/lokasi pengambilan sampel, penimbunan debu dan polusi $\mathrm{Pb}$ dari kendaraan bermotor, bahan bakar minyak, buangan limbah rumah tangga, pestisida kimia.

Pengaruh CAM dan kompos dalam menurunkan kadar $\mathrm{Pb}$ dan $\mathrm{Cd}$ pada tanah yang telah ditanami selada disajikan pada
Tabel 2. Hasil analisis kandungan $\mathrm{Pb}$ dan $\mathrm{Cd}$ setelah pemberian CAM dan kompos menunjukkan bahwa pemberian CAM tidak mampu mereduksi secara nyata konsentrasi $\mathrm{Pb}$ dan $\mathrm{Cd}$. Konsentrasi kedua logam berat tersebut setelah aplikasi CAM pada media tanam hanya mengalami penurun yang sangat sedikit. Hal ini diduga karena konsentrasi $\mathrm{Pb}$ dan $\mathrm{Cd}$ yang terdapat dalam media tanam yang terlalu tinggi dan melampui ambang batas yang disyaratkan yaitu $2 \mathrm{ppm}$.

Tabel 3. Hasil Analisis kandungan $\mathrm{Pb}$ dan Cd pada tanah setelah Perlakuan CAM

\begin{tabular}{ccc}
\hline Perlakuan & \multicolumn{2}{c}{$\begin{array}{c}\text { Kandungan Logam } \\
\text { Berat }(\mathbf{m g} / \mathbf{k g})\end{array}$} \\
\cline { 2 - 3 } & $\mathbf{P b}$ & $\mathbf{C d}$ \\
\hline JoMo & 133,723 & 2,197 \\
JoM1 & 94,581 & 0,680 \\
J1Mo & 138,916 & 0,682 \\
J1M1 & 123,643 & 0,679 \\
J2Mo & 133,990 & 1,439 \\
J2M1 & 133,723 & $\mathrm{Tt}$ \\
\hline
\end{tabular}

Menurut Alloway (1990) pemasok logam berat dalam tanah pertanian antara lain bahan agrokimia (pupuk dan pestisida), asap kendaraan bermotor, bahan bakar minyak, pupuk organik, buangan limbah rumah tangga, industri dan pertambangan. Kondisi tanah persawahan yang terletak di jalur padat transportasi dan lahan yang mendapat perlakuan pemupukan kimia dan pestisida yang sangat tinggi diduga penyebab tingginya akumulasi logam berat tanah yang terletak di jalur utara SulawesiSelatan. Letak persawahan yang berdekatan dengan beberapa industri seperti bengkel, pabrik dan rumah penduduk merupakan sumber pemasok $\mathrm{Pb}$ dan $\mathrm{Cd}$ pada lingkungan tanah baik secara langsung maupun tidak langsung.

Logam berat dalam tanah pertanian dapat memurunkan produktivitas tanah dan mutu hasil pertanian. Selain itu, logam berat dapat terakumulasi pada produk pertanian 
akan membahayakan kesehatan manusia melalui komsumsi pangan yang tercemar.

Logam berat $\mathrm{Pb}$ dan $\mathrm{Cd}$ yang terakumulasi dalam jaringan tanaman melalui dua cara yaitu penyerapan melalui akar dan daun tanaman. Logam $\mathrm{Pb}$ dan $\mathrm{Cd}$ yang diserap oleh akar rambut akan mengalami pengikatan, inaktifasi, dan pengendapan (Lepp, 1978 dalam Endes 1998). $\mathrm{Pb}$ akan diikat oleh organophosphat di dalam inti akar tanaman, sehingga konsentrasi $\mathrm{Pb}$ dan $\mathrm{Cd}$ di akar atau pada umbi yang terserap mellaui tanah lebih rendah. Sedangkan penyerapan melalui daun terjadi karena partikel $\mathrm{Pb}$ dan $\mathrm{Cd}$ di udara jatuh dan mengendap pada permukaan daun. Ukuran stomata daun yang lebih besar (panjang 10 $\mu \mathrm{m}$ dan lebar 2-7 $\mu \mathrm{m}$ ) daripada ukuran partikel $\mathrm{Pb}$ (kurang dari $4 \mu \mathrm{m}$ ) memungkinkan $\mathrm{Pb}$ masuk kedalam jaringan daun melalui celah stomata. Setelah $\mathrm{Pb}$ berada dalam jaringan akan terjadi penumpukan diantara sel jaringan pagar atau jaringan akar (Baker dan Allen 1978 dalam Widriani, 1996. Oleh sebab itu kandungan logam berat $(\mathrm{Pb}$ dan $\mathrm{Cd})$ lebih tinggi pada jaringan daun dibandingkan dengan jaringan lain) misalnya umbi dan akar.

Hasil analisis terhadap kandungan $\mathrm{Pb}$ dan $\mathrm{Cd}$ pada jaringan tanaman pada perlakuan infeksi CAM dan tanpa infeksi CAM diperlihatkan pada Tabel 4 .

Tabel 4. Hasil analisis kandungan $\mathrm{Pb}$ dan $\mathrm{Cd}$ pada Jaringan Tanaman Selada

\begin{tabular}{ccc}
\hline Perlakuan & \multicolumn{2}{c}{$\begin{array}{c}\text { Kandungan Logam } \\
\text { Berat }(\mathbf{m g} / \mathbf{k g})\end{array}$} \\
\cline { 2 - 3 } & $\mathbf{P b}$ & $\mathbf{C d}$ \\
\hline JoMo & 0,488 & 0,338 \\
JoM1 & 0,490 & 0,339 \\
J1Mo & 2,921 & 0,337 \\
J1M1 & 2,944 & 0,340 \\
J2Mo & 2,915 & 0,336 \\
J2M1 & 2,956 & 0,341 \\
\hline
\end{tabular}

Berdasarkan hasil analisis pada Tabel 4, tidak ada perbedaan yang bermakna pada Kadar $\mathrm{Pb}$ dan $\mathrm{Cd}$ dalam jaringan tanaman selada baik yang ditanam pada tanah yang telah diberi CAM maupun tanpa diberi CAM. Hasil diatas menunjukkan bahwa kandungan $\mathrm{Pb}$ pada jaringan daun diatas ambang batas yang disyaratkan yaitu 2 ppm pada tanaman Caisim/sejenis tanaman sayuran daun seperti sawi hijau dan untuk Cd batas aman untuk bawang merah adalah $0,1 \mathrm{ppm}$. Dari data diatas semua perlakuan menunjukkan bahwa kadar logam berat berada diatas ambang batas keamanan pangan, lebih khusus lagi tanaman selada dimakan sebagai lalapan mentah sehinggah logam berat tidak sempat larut dalam proses pengolahan ataupun penyimpanan.

Tingginya kandungan logam berat pada jaringan tanaman karena kadar $\mathrm{Pb}$ dan Cd yang sangat tinggi dalam tanah melebih ambang batas yang dipersyaratkan. Pemberian CAM dengan dosis 10 gr per pot belum efektif dalam mereduksi kadar $\mathrm{Pb}$ dan Cd dalam tanaman. Selain itu mikoriza dan kompos yang merupakan pupuk hayati membutuhkan waktu yang lebih panjang untuk terdekomposisi dalam tanah dan membantu proses penjerapan logam-logam berat pada tanah-tanah tercemar. Waktu penelitian yang singkat (6 minggu) belum cukup untuk proses kolonisasi CAM dan dekomposisi bahan organik dalam tanah.

Faktor lain yang mempengaruhi kadar $\mathrm{Pb}$ dan $\mathrm{Cd}$ dalam tanaman adalah umur tanaman, morfologi dan fisiologi tanaman, kandungan $\mathrm{Pb}$ dalam tanah dan factor yang mempengaruhi lahan seperti banyaknya tanaman penutup serta jenis tanaman penutup disekitar tanaman tersebut.

\section{KESIMPULAN}

Berdasarkan hasil penelitian diketahui (1) kandungan $\mathrm{Pb}$ dan $\mathrm{Cd}$ pada tanah dijalur utara telah melewati ambang batas dengan 15 meter dari jalan raya adalah 158,621 $\mathrm{mg} / \mathrm{kg}$ dan $1,434 \mathrm{mg} / \mathrm{kg}$. Sedangkan untuk tanah yang berjarak 30 meter kadar $\mathrm{Pb}$ dan Cd adala $143,842 \mathrm{mg} / \mathrm{kg}$ dan $1,439 \mathrm{mg} / \mathrm{kg}$, (2). Terjadi penurunan kandungan $\mathrm{Pb}$ dan $\mathrm{Cd}$ setelah perlakuan cendawan mikoriza arbuskular tapi penurunannya tidak 
signifikan dibanding dengan tanpa perlakuan mikoriza dan (3). Kandungan Cd dan $\mathrm{Pb}$ pada tanaman selada yang ditanam pada berbagai perlakuan media dan penambahan CAM diatas ambang batas konsentrasi aman untuk dikomsumsi.

Disarankan untuk menggunakan mikoriza dan pupuk organik untuk mengurangi kandungan $\mathrm{Pb}$ dan $\mathrm{Cd}$ pada bahan pangan, khususnya sayuran mentah dan mengurangi penggunaan pupuk kimiawi dan pestisida kimia pada lahan-lahan pertanian karena merupakan pemasok logam berat utama pada tanah pertanian untuk mereduksi pencemaran $\mathrm{Pb}$ dan $\mathrm{Cd}$ pada sawah di jalur utara Sulawesi-Selatan.

\section{PUSTAKA}

Ali, G.M., EF.Husin, N.Hakim dan Kusli, 1997. Pemberian Mikoriza Vesikular Arbuskular untuk Meningkatkan Efisiensi Pemupukan Fosfat Tanaman Padi Gogo pada tanah Ultisol dengan perunut 32P.p. 597-605 dalam Subagyo et al (Eds). Prosiding Kongres Nasional VI HITI, Jakarta, 12-15 Desember 1995

Alloway, B.J. 1990. Heavy Metal in Soils. John Willey and Sons, New York.

Darmono, 1995. Logam dalam system Biologi Makhluk Hidup. UI-Press, Jakarta.

Endes, N.D. 1989. Studi kemampuan tanaman dalam menjerap timbale emisi dari kendaraan bermotor. Tesis. Fakultas Pascasarjana IPB, Bogor.

Iriani Farida, 2003. Identifikasi Cendawan Mikoriza serta pengaruhnya terhadap pertumbuhan stek tebu yang ditanam pada media bekas pertanaman padi gogo dan ubi kayu bermikoriza.. Prosiding Seminar Nasional Mikorisa, Bandung.

Kemeterian Negara Lingkungan Hidup, Republik Indonesia,
2007.Peluncuran Laporan Status Lingkungan Hidup Indonesia. KLH RI, Jakarta

Subowo, Tuberkih E, Kurniawansyah, A.M. dan Nasution, I. 1999. Identifikasi dan Pencemaran Kadmium (Cd) untuk padi gogo. Prosiding Seminar Nasional Sumber Daya Lahan. Pusat Penelitian Tanah dan Agroklimat Bogor.

Widriani, R. 1996. Kandungan Timbal pada Tanaman Teh dan Tanah di Perkebunan Gunung Mas Bogor. Tesis Fakultas PascaSarjana IPB, Bogor. 